\title{
Weather Conditions Associated with Corn Simulated Yield in the Corn Belt of Northeastern China during the Past Three Decades
}

\author{
Zeng-hui SUN \\ Shaanxi Province Land Engineering Construction Group, \\ Xi'an 710075, China \\ Key Laboratory of Degraded and Unused Land \\ Consolidation Engineering, the Ministry of Land and \\ Resources of China, \\ sunzenghui061@126.com
}

\begin{abstract}
The Corn Belt of Northeastern China (CBNC) accounts for about $35 \%$ of the nation' corn production in China. In the past three decades, corn yield in CBNC have increased under changing in climate and crop management. It is important to investigate the contribution of these changing factors to the historical yield increases to improve our understanding of how we can ensure increased yield in the future. In this paper we conducted correlation and regression analyses of climate and simulated corn yield over the period 1980 to 2011 in CBNC. It was found that over three decades, the daily mean, minimum temperature and growing degree days (GDD) per ten year increased at a rate of $0.37^{\circ} \mathrm{C}, 0.47^{\circ} \mathrm{C}$ and $51^{\circ} \mathrm{C}$, respectively. In contrast, the relative humidity and daily mean wind speed decreased gradually at a rate of 0.18 and $1.8 \mathrm{~km} \mathrm{day}^{-1}$, respectively. Not significant change in precipitation was found, although differences between years were large. The daily minimum temperature and solar radiation were the dominant factor to corn potential production. According to a regression analysis of the corn potential yield and the climate factors, the results indicate that corn potential yield decreased 1010 and $1314 \mathrm{~kg} \mathrm{ha}^{-1}$ for each $1^{\circ} \mathrm{C}$ increase growing season mean and minimum temperature, respectively; rain-fed yield declined 2819 and $2437 \mathrm{~kg} \mathrm{ha}^{-1}$ for each increase $1^{\circ} \mathrm{C}$ growing season mean and maximum temperature, respectively. To further improve the potential yield of corn in the coming decades, efforts should be paid to break the potential ceiling reduce the yield gaps by breeding higher yield variety and introduction of new agricultural technology.
\end{abstract}

Keywords-RZWQM; Corn Belt of Northeastern China; potential yield; yield gaps; weather descriptors

\section{INTRODUCTION}

Northeastern China, one of the main agricultural regions of the country, accounts for $19 \%$ and $30 \%$ of the nation's total cultivated land and crop yield, respectively [1]. In the past few decades, corn yields in the region increased rapidly due to newer cultivar and management improvements [2], such as fertilization [3], corn plastic mulching [4]. Moreover, Climate change has a crucial influence on crops because growth and development are affected by sunlight, temperature, and water.

\author{
Zhe LIU* \\ Shaanxi Province Land Engineering Construction Group, \\ Xi'an 710075, China \\ Key Laboratory of Degraded and Unused Land \\ Consolidation Engineering, the Ministry of Land and \\ Resources of China, \\ liuzhe168@126.com \\ *Corresponding author
}

The effect of climate change on crop production depends on the interaction of various climatic factors and agricultural management parameters. Advancing corn productivity of CBNC will play an important role in ensuring China's and global food security. However, this will be a big challenge under the warming future climate [5]. Although, many previous studies showed that crop production might benefit from future warming if suitable adaptations are conducted for cropping system [6-7]. Effects of temperature increase on crop production, however, can be either negative or positive, which it was depending on the region. Therefore, a better understanding of these yield increases under a changing climate in Northeast China (NEC) will help ensure sustainable yield in the future. Correlation analysis of historical climate data and crop yield records has been successfully and widely used in establishing relationships between crop production and climate change. Some studies used advanced statistical methods and regression analysis to separate the contributions of climate factors, crop variety, management, etc. on yield variations leading to a better understanding of the effects of historical climate change [8]. Along these lines, we performed a simple correlation analysis to study the relationship between corn growth and the key climate factors during the crop growing season in CBNC from 1980 to 2011. Our objectives were to learn which variables of climate change in the crop growing season were associated with potential yield and rain-fed yield over this 32-year period.

\section{MATERIALS AND METHODS}

The study site, Siping, is located in the center of the Corn Belt of Northeastern China. this region is in the north temperate zone and have a semi-humid continental monsoon climate with an average (1980-2011) annual temperature of $5.9^{\circ} \mathrm{C}$, annual sunshine hours of $2679 \mathrm{~h}, 142 \mathrm{~d}$ frost-free period, annual cumulative temperature $\left(>10^{\circ} \mathrm{C}\right)$ of $3078^{\circ} \mathrm{C}$, annual precipitation of $573 \mathrm{~mm}(65 \%$ of annual precipitation occurs from June to August), and mean annual pan evaporation of $808 \mathrm{~mm}$. The soil is frigid Typic Haplustoll with sandy loam texture, formed from Aeolian.

For the correlation analysis, the growing season average daily mean (Tm), maximum (Tmax), minimum (Tmin) 
temperature, growing season total precipitation $(\mathrm{P})$, relative humidity $(\mathrm{RH})$, daily average wind speed and daily average sunshine hours $(\mathrm{SH})$, daily solar radiation $(\mathrm{Rn})$ and growing degree days (GDD) were defined as the descriptor variables. The nine data sets during the crop growing season were calculated to determine the climate change trends since 1980 . Liner regression analysis was used to analyze the trend of change in climatic variables. Relation between crop growth indicators (the yield, biomass, HI and yield gaps) and the descriptors of the growing season climate was assessed by means of linear correlation. Correlation coefficients represented by $r$ and $p$-values with $p<0.05$ considered as significant.

\section{RESULTS}

\section{A. Historical Trend of Climate Change during Corn Growing Season}

During 1980 to 2011, Northeast China experienced a significant climate change during the corn growing season May-September (Fig. 1). The daily mean, minimum temperature and growing degree days (GDD) per year increased at a rate of $0.037,0.047$ and $5.1^{\circ} \mathrm{C}$, respectively. For temperature, the most significant changes were the increase in mean and minimum temperature. The maximum temperature showed a slight increasing trend during the corn growing season, although this increase was not significant. The increase in minimum temperature led to significant increase in mean temperature. The mean temperature in NEC increased $0.037^{\circ} \mathrm{C}$ per year, which was consistent with the findings of Liu et al. [9], and higher than the average value of $0.22{ }^{\circ} \mathrm{C}$ for China. This result was consistent with the finding by the Intergovernmental Panel on Climate Change, which indicates that the high latitude area of the northern hemisphere was the most susceptible to climate change. In contrast, the relative humidity and daily mean wind speed decreased gradually at a rate of 0.18 and 1.8 , respectively. Over the same thirty-two year precipitation showed a slight decreasing trend, although this decrease was not significant, large annual variations were found during these years, especially 1995, with a highest value was $776 \mathrm{~mm}$ and a lowest was $198 \mathrm{~mm}$. precipitation varied hugely among years and the CV was as high as $29.0 \%$. The daily average solar radiation and sunshine hours decreased slightly during the 32 years, but the change were not significant among years with the CV were $3.4 \%$ and $6.4 \%$, respectively.
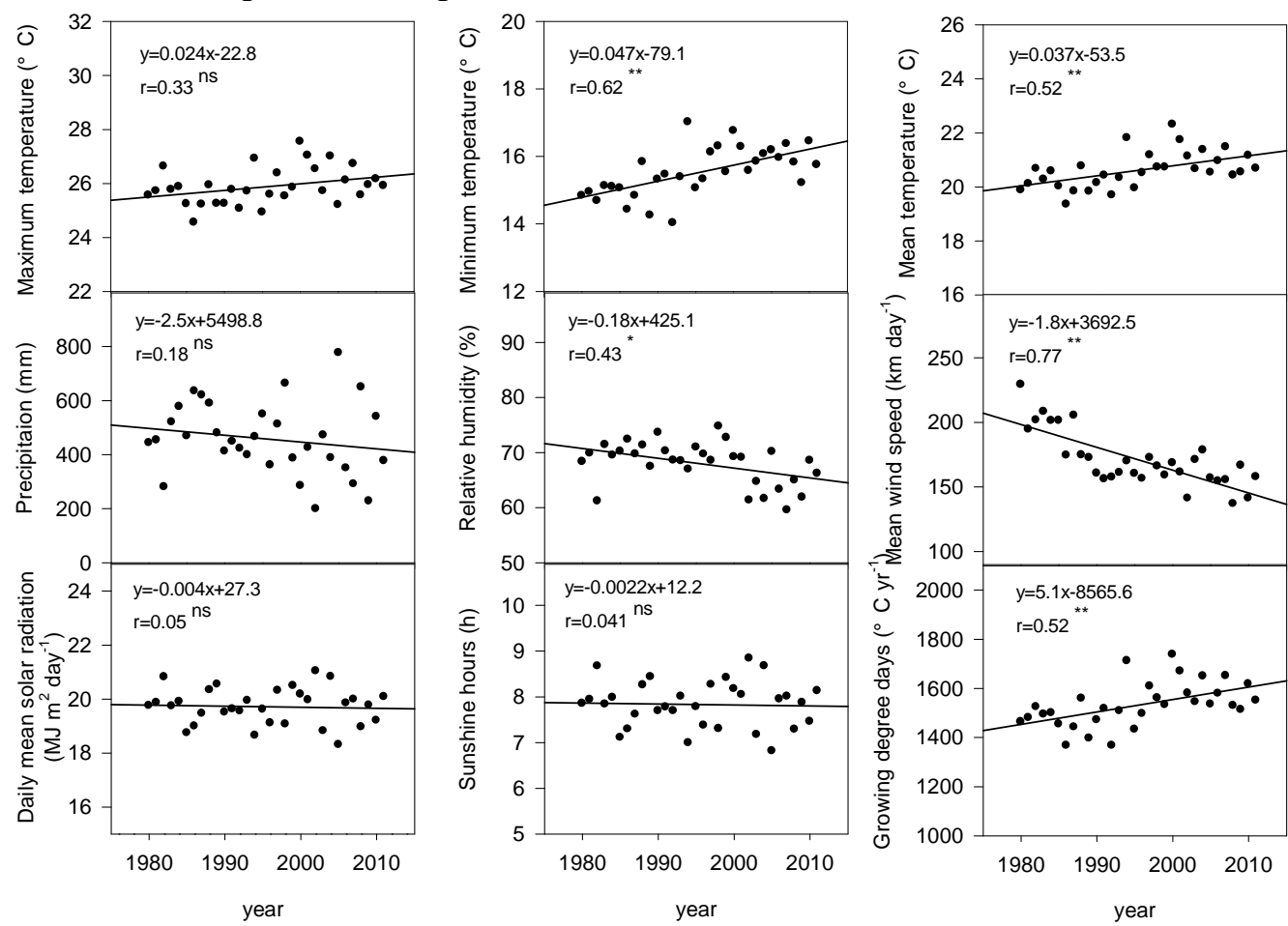

Figure 1. Historical trends in maximum temperature $\left(\mathrm{a},{ }^{\circ} \mathrm{C}\right)$, minimum temperature $\left(\mathrm{b},{ }^{\circ} \mathrm{C}\right)$, daily mean temperature $\left(\mathrm{c},{ }^{\circ} \mathrm{C}\right)$, precipitation $(\mathrm{d}$, mm), relative humidity $(\mathrm{e}, \%)$, daily mean wind speed $\left(\mathrm{f}, \mathrm{km} \mathrm{day}^{-1}\right)$, daily mean solar radiation $\left(\mathrm{g}, \mathrm{MJ} \mathrm{m}^{2}\right.$ day- $\left.{ }^{1}\right)$, daily mean sunshine hours $(\mathrm{h}, \mathrm{h})$ and growing degree days $\left(\mathrm{i},{ }^{\circ} \mathrm{C}\right.$ ) over the corn growing season during 1980-2011 in Northeast China. ${ }^{* *}$ Trends significant at $P<0.001$, and *trends significant at $P<0.05$. 


\section{B. Relationships between Corn Growing Indicators and Climatic Variables}

In order to identify the main climatic factors associated with corn growing indicators (including yield, biomass, harvest index (HI) and yield gaps), a Pearson correlation analysis was carried out between those corn growing indicators and maximum temperature (Tmax), minimum temperature (Tmin), daily mean temperature (Tm), precipitation $(\mathrm{P})$, relative humidity $(\mathrm{RH})$, daily mean wind speed (WS), daily mean solar radiation (Rn), daily mean sunshine hours (SH) and growing degree days (GDD) over the corn growing season for the 1980 to 2011 (Table 1). The effect of Tmin, Tm, and GDD on potential yield of corn were very significant $(P<0.01)$, and the $\mathrm{Rn}$ and $\mathrm{SH}$ were significant $(P<0.05)$. This means that temperature especially minimum temperature and the GDD were the major climate limiting factors for corn potential yield in Northeast China. There were very significant $(P<0.01)$ correlation between rain-fed yield and Tmax, Tm, precipitation, and $\mathrm{RH}$, and a significant $(P<0.05)$ relationship existed between rain-fed yield and $\mathrm{Rn}$ and sunshine hours. This means that maximum temperature, precipitation and RH were the major climate limiting factors for corn rain-fed yield in this region. It was found that the Tm, Rn and SH were significant related with potential biomass. There were significant correlation between rain-fed biomass and Tmax, Tm, precipitation, and $\mathrm{RH}, \mathrm{Rn}$, sunshine hours and GDD. The HI in the no water stress condition correlated significantly with Tmax, Tmin, $\mathrm{Tm}$ and GDD. In contrast, the $\mathrm{HI}$ in water limiting condition was only correlated significantly with the relative humidity. There were significant correlation between yield gaps and Tmax, precipitation, and $\mathrm{RH}, \mathrm{Rn}$ and sunshine hours.

\section{DISCUSSION AND CONCLUSIONS}

The study site, Siping, is centrally located in the Corn Belt of Northeastern China. During the past three decades, temperature and growing degree increased significantly and relative humidity and daily mean wind speed decreased gradually. The daily average solar radiation and sunshine hours decreased slightly a small extent during the 32 years, but the changes were not significant. A significant, negative correlation was found between corn potential production and the temperatures (especially minimum temperature) and GDD during the full crop growing season, but positive with solar radiation and sunshine hours. This finding is consistent with that predicted by Chen et al. [10]. Over the last 32 years, if there was no change in the cultivars grown by farmers and no improvement in management practices, the simulations in our study indicate that climate change would have caused a negative impact on potential yields and biomass of corn in CBNC. Because the warmer climate would accelerate the crop development, speed up the maturation of crops and lead to reduction in the length of the growing season, and the therefore a shorter time for processes like photosynthesis and the filling of grain lead to a negative impact on crop yield if there is no hybrid change [11]. The result was similar with some previous researches $[10,12]$. Furthermore, our results indicate that corn potential yield decreased 1010 and $1314 \mathrm{~kg}$ ha-1 for each $1^{\circ} \mathrm{C}$ increase growing season mean and minimum temperature, respectively. This finding was consistent with that predicted by Liu et al. [9] and Wang et al. [13] in CBNC. For United Sates, previous modeling studies predict that potential yield of corn declines by $11-22 \%$ for a $3^{\circ} \mathrm{C}$ temperature increase [14]. Moreover, corn showed negative impacts for global net loss of $3.8 \%$ since 1980 to 2008 at the global scale, which indicated than corn potential yield declined by $8.3 \%$ for each $1^{\circ} \mathrm{C}$ increase in mean minimum and maximum temperatures during the full crop growing season[12]. However, Chen et al. [7] indicated that the yields increased with minimum temperature during the full crop growing season, especially during the months May and September in CBNC. However, in CBNC, yields of corn have steadily increased since the 1980s since options for autonomous adaptation were realized by farmers [7, 9]. As a result, the yield of corn increased with time in CBNC indicating cultivar selection (i.e., stabilized or extended phonological durations) and improved management (i.e., increased pant density) played a critical important role in increasing the corn yield.

In this study, we analyzed the effects of the change climatic variables on the rain-fed corn production. A significant, negative correlation was found between corn rain-fed production and the temperatures (especially maximum temperature) and GDD during the full crop growing season, but positive with precipitation, relative humidity, solar radiation and sunshine hours. Compared with the potential corn production, the rain-fed production was susceptible to maximum temperature, precipitation, and relative humidity, and the result was showed that relative humidity had a stronger effect than precipitation. Previous research suggested that, in the future, the increasing in precipitation in CBNC will help to improve the water supply, and will increase the crop yields; however, the increased precipitation will still be insufficient to compensate for the increasing in evapotranspiration caused by warming. Thus, there was still insufficient water during corn growing season in CBNC, and the corn production will be affected in areas without irrigation [15]. Higher temperature may have a negative effect on yields when they exceed $35^{\circ} \mathrm{C}$, but this is not a matter of concern so far as the maximum temperature in Northeast China is not higher than $30^{\circ} \mathrm{C}$ [7]. However, in a more distant future, when maximum temperature continues to raise, more attention, therefore, needs to be paid to the negative effect on yields. In this study, maximum temperature increasing lead to the rain-fed corn yield decline; this perhaps for two reasons; first, the maximum temperature increasing accelerate the crop development; and second, the continuous warning of climate would increase evapotranspiration, the drought stress for corn growing might aggravate under the rain-fed condition. Precipitation in full crop growing season showed a slight decreasing trend, although this decrease was not significant. Therefore, additional action may be needed to the impacts of precipitation variation. Although the annual precipitation in the region of 400 to $1000 \mathrm{~mm}$ basically fills the requirements for corn growth and development [16], extremes such as 
droughts in May and heavy rainfall in July and August do currently happen [17].

In summary, it was shown that expected changing climate will reduce future corn production in the Corn Belt of Northeastern China if there is no hybrid change and no improvement and innovation in the management. In order to benefit the climate change on crop productivity, a comprehensive adaptation strategy should be taken. The integrated strategy can include the following practices: (1) optimize cropping season via adjusting sown date and delaying the harvest date to allow crop development during more favorable conditions; (2) improve a newer cultivar which has a longer growing period, especially for the period of grain fill, that increases the length of time devoted to yield accumulation; (3) selection of new cultivars with higher photosynthesis rate and advances in biotechnology, seed genetics and agricultural technology that breed new highyielding varieties; (4) increase water use efficiency through conservation tillage practices, combining plastic-mulched ridge and furrow planting for harvesting rainfall and conserving water and reduced or no-tillage which will improve water availability to the crop; (5) improve soil quality, over the past decades, soil quality in $\mathrm{CBNC}$ has become poor, especially with respect to soil organic carbon (SOC). A higher SOC content will improve the resistance of soil to adverse climate conditions and increase stability.

In our study, we only analyzed the effects of the changing climate on the corn production in Aeolian sandy soil. A subsequent study should quantify the influence of the soil condition, changes in other climate variable. These factors were not considered in this study, but they might influence the variation of corn potential and rain-fed production.

TABLE I. CORRELATION COEFFICIENTS BETWEEN CLIMATIC FACTORS OF CORN GROWTH SEASON AND CORN GROWING INDICATORS DURING 1980-2011 IN NORTHEAST CHINA. $\dagger$

\begin{tabular}{|c|c|c|c|c|c|c|c|c|c|}
\hline & Tmax & Tmin & Tmean & P & RH & WS & Rn & SH & GDD \\
\hline $\mathrm{Yp}$ & $\mathrm{ns}$ & $* *$ & $*$ & $\mathrm{~ns}$ & $\mathrm{~ns}$ & $\mathrm{~ns}$ & $*$ & $*$ & $* *$ \\
\hline $\mathrm{Yr}$ & $* *$ & $\mathrm{~ns}$ & $* *$ & $* *$ & $* *$ & $\mathrm{~ns}$ & $*$ & $*$ & $*$ \\
\hline $\mathrm{Bp}$ & $\mathrm{ns}$ & $* *$ & $\mathrm{~ns}$ & $\mathrm{~ns}$ & $\mathrm{~ns}$ & $\mathrm{~ns}$ & $* *$ & $* *$ & $\mathrm{~ns}$ \\
\hline $\mathrm{Br}$ & $* *$ & $\mathrm{~ns}$ & $* *$ & $* *$ & $* *$ & $\mathrm{~ns}$ & $*$ & $*$ & $* *$ \\
\hline $\mathrm{HIp}$ & $*$ & $* *$ & $* *$ & $\mathrm{~ns}$ & $\mathrm{~ns}$ & $\mathrm{~ns}$ & $\mathrm{~ns}$ & $\mathrm{~ns}$ & $* *$ \\
\hline $\mathrm{HIr}$ & $\mathrm{ns}$ & $\mathrm{ns}$ & $\mathrm{ns}$ & $\mathrm{ns}$ & $* *$ & $\mathrm{~ns}$ & $\mathrm{~ns}$ & $\mathrm{~ns}$ & $\mathrm{~ns}$ \\
\hline $\mathrm{YG}$ & $*$ & $\mathrm{~ns}$ & $\mathrm{~ns}$ & $* *$ & $* *$ & $\mathrm{~ns}$ & $* *$ & $* *$ & $\mathrm{~ns}$ \\
\hline
\end{tabular}

$\dagger \mathrm{Yp}$ is potential yield, $\mathrm{Yr}$ is rain-fed yield, $\mathrm{Bp}$ is potential biomass, $\mathrm{Br}$ is rain-fed biomass, HIp is potential harvest index, HIp is rain-fed harvest index and YG is the gaps by potential yield minus rain-fed yield. GDD = (maximum temperature + minimum temperature) $/ 2-\mathrm{T}$. $\mathrm{T}=10^{\circ} \mathrm{C}$. GDD was set to be $0^{\circ} \mathrm{C}$ when it was less than $0^{\circ} \mathrm{C}$. ${ }^{*}$ Significant at $\mathrm{P}<0.05$, ** Significant at $\mathrm{P}<0.1$.

\section{ACKNOWLEDGMENT}

This work was supported by the Shaanxi Focus on science and technology innovation team (no. 2016KCT-23). The authors gratefully acknowledge researchers at the Lishu
Experiment Station of China Agricultural University in Lishu country in Jilin province, and at the Key Laboratory of Degraded and Unused Land Consolidation Engineering, the Ministry of Land and Resources of China, for their help with the experiments.

\section{REFERENCES}

[1] D. W. Liu, Z. M. Wang, B. Zhang, et al., "Spatial distribution of soil organic carbon and analysis of related factors in croplands of the black soil region, northeast China". Agriculture, Ecosystems and Environment, vol. 113, pp. 73-81, 2006.

[2] Y. R. Yun, X. Q. Fang, Y. Wang, J. D. Tao, D. F. Qiao, "Main grain crops structural change and its climate background in Heilongjiang province during the past two decades". Journal of Natural Resources, vol. 20, pp. 697-705, 2005.

[3] Q. Gao, G. Z. Feng, Z. G. Wang, "Present situation of fertilizer application on spring maize in Northeast China". Chinese Agricultural Science Bulletin, vol. 26, pp. 229-231, 2010.

[4] L. W. Ma, R. W. Malone, P. Heilman, "RZWQM simulated effects of crop rotation, tillage, and controlled drainage on crop yield and nitrate-N loss in drain flow”. Geoderma, vol. 140, pp. 260-271, 2007.

[5] Y. Liu, E. Wang, X. G. Yang, "Contributions of climatic and crop varietal changes to crop produciton in the North China Plain, 1980". Global Change Biology, vol. 16, pp. 2287-2299, 2010.

[6] D. Lobell, M. Burke, C. Tebaldi, M. D. Mastrandrea, "Prioritizing climate change adaptation needs for food security in 2030". Science, vol. 319, pp. 607-610, 2008.

[7] C. Q. Chen, C. X. Lei, A. X. Deng, "Will higher minimum temperatures increase corn production in Northeast China? An analysis of historical data over 1965-2008". Agricultural and Forest Meteoroloy, vol. 151, pp. 1580-1588, 2011.

[8] A. Bhatia, H. Pathak, P. K. Aggarwal, "Trade-off between productivity enhancement and global warming potential of rice and wheat in India”. Nutrient Cycling in Agroecosystems, vol. 86, 413424, 2010.

[9] Z. J. Liu, X. G. Yang, F. Chen, "The effects of past climate change on the northern limits of maize planting in Norhteast China". Climatice Change. vol. 117, 891-902, 2013.

[10] X. C. Chen, F. Chen, Y. L. Chen, "Modern maize hybrids in Northeast China exhibit increased yield potential and resource use efficiency despite adverse climate change". Global Change Biology, vol. 19, 923-936, 2013.

[11] J. E. Olsesen, M. Bindi, "Consequences of climate change for European agricultural productivity, land use and policy". European Journal of Agronomy, vol. 16, 239-262, 2002.

[12] D. B. Lobell, C. B. Field, "Global scale climate-crop yield relationships and the impacts of recent warming". Environmental Research Letter, vol. 2, 1-7, 2011.

[13] J. Wang, E. L. Wang, H. Yin, "Declining yield potential and shrinking yield gaps of maize in the North China Plain". Agricultural and Forest Meteoroloy, vol. 195, 89-101, 2014.

[14] R. A. Brown, N. J. Rosenberg, "Sensitivity of crop yield and water use to change in a range of climatic factors and $\mathrm{CO}_{2}$ concentrations: a simulation study applying EPIC to the central USA". Agricultural and Forest Meteoroloy, vol. 83, 171-203, 1997.

[15] J.D. Wu, S.L. Wang, J.M. Zhang, "A numerical simulation of the impacts of climate change on water and thermal resources in Northeast China". Resources Science, vol. 22, 36-42, 2000.

[16] J. F. Xiao, Z. D. Liu, Y. M. Chen, "Study on the water requirement and water requirement regulation of maize in China". Journal of Maize Sciences, vol. 16, 21-25, 2008.

[17] X. J. Lu, Z. Z. Li, Q. G. Bu, "Effects of rainfall harvesting and mulching on corn yield and water use in the corn belt of northeast china”. Agronomy Journal, vol. 106, 2175-2184, 2014. 